\title{
Consumer Network and Market Dynamics
}

\author{
Satoshi Itoh \\ Yasuyuki Murakami \\ Takashi Iba \\ Faculty of Policy Management, Keio University
}

\begin{abstract}
This paper suggests that the interaction between consumers has an impact on market structure, in addition to each consumer's own behavior. In this paper, we replicate the artificial market model proposed by Onozaki and Yanagita, and extend it by adding the network of consumers in order to show that the interaction between consumers in the market affects emerging and changing the market structure. Onozaki-Yanagita model, which is made under the idea that oligopolistic state in a market is the result of competitive situations, shows monopoly and oligopoly come out of them. We put various network structures of consumers to the model, and realize that the interaction between consumers influences in shaping the market structure.
\end{abstract}

Keywords: Artificial Market, Agent-Based Simulation, Social Network, Market Structure

\section{Introduction}

Oligopolistic state, several big companies are dominating a market while they are scrambling for the market share, is often seen in the actual market. Comparing this state with the idea of "Perfect Competition" in micro-economics, this can be considered as a suffocate factor in a competitive market. However, it can be considered that the existence of monopoly and oligopoly is a consequence of share competition. It is able to say that a company which comes through a competitive market acquires high share in a market.

Under this idea, Onozaki and Yanagita made an artificial market model, which focuses on an industry with many consumers and companies, and play it as simulation experiment[1]. This simulation shows that monopoly and oligopoly emerge from competitive situations.

In this paper, we replicate and extend this model on PlatBox Simulator [2, 3], adding the network of the relation between consumers, and play it as simulation experiment. This is because we think that the interaction between consumers will be important when thinking about market structure emerging and changing.

\section{Onozaki-Yanagita Model}

Onozaki-Yanagita model focuses on an industry consisting of many consumers and companies, labeled as $i=1,2, \ldots, I$ and $j=1,2, \ldots, J$. Each consumer has a preference to a certain company, and purchases products by doing a comparison of favorite company's and another company's. If a consumer finds another company's product better than the favorite company's one, then a consumer switches his favorite company to it. Companies take their own profit as feedback from consumers, and modify their business strategies. Based on these strategies, companies produce products and sell it to consumers again. By doing these actions over and over again, the market share of each company's shifts gradually in a market, and this model shows that monopolistic and oligopolistic market structure emerging from competitive market.

There are three characteristics of this model.

- Company adapts its own business strategies.

- Consumer has a certain preference.

- Company and consumer have bounded rationality behavior.

\subsection{Company's Adaptive Behavior}

In this model, company has an adaptive behavior. Each company produces and sells its products, calculates its own profit, and sets its next strategy based on the profit it earned.

Producing and Selling Products Company sets its price of $t$-th period $p_{i_{t}}$ and production of $t$-th period $q_{i_{t}}$ at the end of $(t-1)$-th period. At $t$ th period, it produces and sells its products, which only last for the $t$-th period.

Sale of $i$-th company's products $s_{i_{t}}$ is smaller one of either the demand for $i$-th company's products $D_{i_{t}}$ or the production $q_{i_{t}}$. 
Calculating the Profit After the selling, $i$-th company calculates the profit of $t$-th period $\pi_{i_{t}}$ based on price $p_{i_{t}}$, production $q_{i_{t}}$, sale $s_{i_{t}}$, and the cost function $c\left(q_{i_{t}}\right)$.

$$
\begin{gathered}
\pi_{i_{t}}=p_{i_{t}} s_{i_{t}}-c\left(q_{i_{t}}\right) \\
c\left(q_{i_{t}}\right)=1.0+0.1 * q_{i_{t}}^{2}
\end{gathered}
$$

Setting the Next Strategy Based on the calculated profit, company considers whether its strategy was right or not, and sets its price of next period $p_{i_{t+1}}$ and production of next period $q_{i_{t+1}}$.

If $\pi_{i_{t}}$ is higher than $\pi_{i_{t-1}}$, company recognizes the vector of setting its price and production was in right direction, and advances $p_{i}$ and $q_{i}$ toward the same direction.

$$
\begin{aligned}
& p_{i_{t+1}}=p_{i_{t}}+\rho \quad \text { or } \quad p_{i_{t+1}}=p_{i_{t}}-\rho \\
& q_{i_{t+1}}=q_{i_{t}}+\rho \quad \text { or } \quad q_{i_{t+1}}=q_{i_{t}}-\rho
\end{aligned}
$$

If $\pi_{i_{t}}$ is lower than $\pi_{i_{t-1}}$, company recognizes the vector of setting its price and production was in the wrong direction, and revises $p_{i}$ and $q_{i}$ toward random directions. When $p_{i_{t+1}} / q_{i_{t+1}}$ goes negative number, it will be set at 0 .

$$
\begin{aligned}
& p_{i_{t+1}}=p_{i_{t}}+\rho \cos \theta \\
& q_{i_{t+1}}=q_{i_{t}}+\rho \sin \theta
\end{aligned}
$$

\subsection{Consumer's Habitual Behavior}

In this model, consumer has a habitual behavior. Each consumer selects a company, which is often his favorite company, and purchases its products.

Selecting a Company Consumer checks the price of his favorite company's product $p_{\sigma_{j} t}$ and another company's $p_{r t}\left(r \neq \sigma_{j}\right)$. It is called comparing company, which is randomly selected beside his favorite company as a reference. Then consumer purchases his favorite company's product unless the ratio of price difference go over a critical level, given as a threshold $k$. Consumer decides which company's product he purchases according to the following equation.

$$
\frac{p_{\sigma_{j} t}-p_{r t}}{p_{\sigma_{j}}} \leq k
$$

If consumer chooses comparing company's, then he change his favorite company to it $\left(\sigma_{j}=\mathrm{r}\right)$.

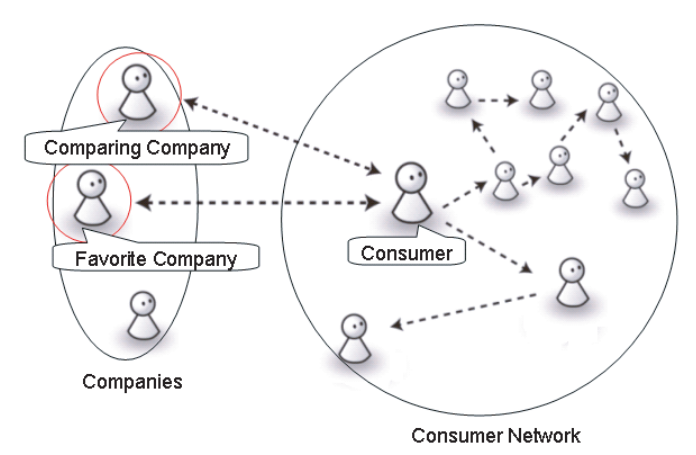

Figure 1: Overview of extended model including the network of consumers

Purchasing Products Based on the price of products consumer chose $p_{i_{t}}$, $j$-th consumer decides the amount of products he will purchase $d_{i j_{t}}$ and place an order with the company. The demand for $i$-th company by $j$-th consumer $d_{i j_{t}}$ is calculated as below.

$$
d_{i j_{t}}=f\left(p_{i_{t}}\right)=0.1 * \exp \left(-0.1 * p_{i_{t}}\right)
$$

\subsection{Simulation Results of Onozaki- Yanagita Model}

From this model, Onozaki and Yanagita reached two conclusions. One is that, short-term monopolistic companies are interchanged heavily, if consumer doesn't have any brand royalty. Long-term companies could exist as well. The other is that, as parameter $k$, which means consumer's brand loyalty, increases, not only monopoly but oligopoly appears. And the duration of either monopoly or oligopoly becomes longer.

\section{$3 \quad$ Extended Model}

In Onozaki-Yanagita model, each consumer compares the product between favorite company and another before purchasing the product. However, following two problems can be pointed out about this model. One is the fact that the mechanism of randomly selecting the comparing company beside favorite company is unrealistic. The other is the fact that there is no interaction between consumers is unrealistic. Each consumer is isolated in this model, but real people will exchange some information through their acquaintances.

To overcome these problems, we added the network of consumers to this model (Figure 1,2). By adding the network of consumers, consumer can take action based on information from acquaintance, when purchasing products. As a network structure of consumers, "Fully Connected Net- 


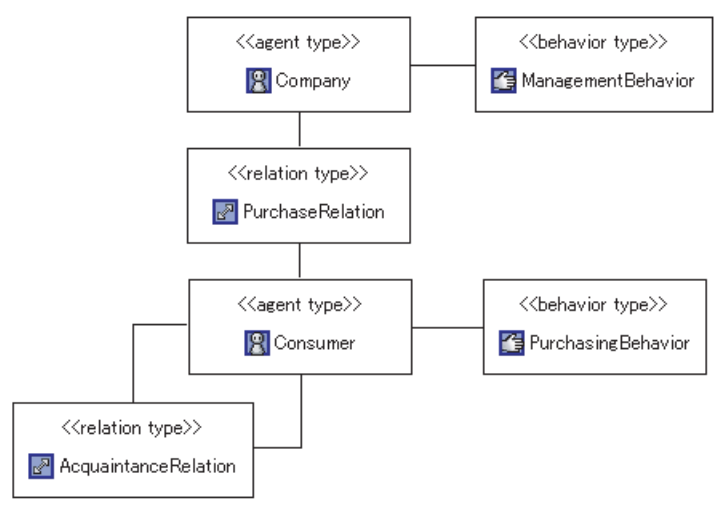

Figure 2: Class diagram of extended model

work", "Random Network", "Small World Network", "Scale Free Network" and "Lattice Network" can be listed.

With this extension of the model, the flow of the model is as below.

1. Company sets price of the product and production based on its own strategy.

2. Each consumer selects a company to compare with favorite company, when purchasing products. As a selection method of the comparing company, there are three methods as follows:

a. Randomly select one from all the companies.

b. Randomly select one from acquaintance's favorite companies.

c. With a certain percentage, method a and b will be selected (Each method will be selected in $50 \%$ in the following experiments).

3. Consumer compares the product of favorite and comparing company. If the price difference is within a certain threshold, consumer selects the favorite company's products. If it is over the threshold, then consumer selects the comparing company.

4. Based on the price, consumer decides the amount to buy and order to the company.

5. After all the consumers finish ordering, each company compares the amount ordered from consumers and its own production, and fixes the sales, which is the lower of the two.

6. Each company calculates the profit from the price, production, sales, and cost function. Then company compares with the last term's its profit to check the efficiency of the strategy. If it is needed, the strategy will be changed.

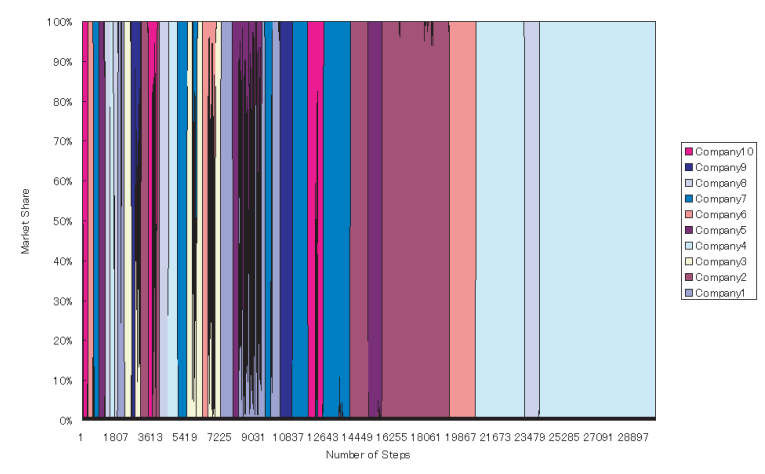

Figure 3: Transition of Each Company's Market Share (Onozaki-Yanagita Model), $k=0.0$

This series of flow will be counted as one step in the simulation. By repeating this step, we are able to analyze how the each company's market share changes, and what kind of market structure will appear.

\section{Simulation Analysis}

In doing this simulation, we set initial condition as follows and play it for 30000 steps:

- $I$ (number of company) $=10$

- $J$ (number of consumer) $=100$

- $p_{1}$ (each company's initial price $)=3$

- $q_{1}$ (each company's initial production $)=0$

- $k$ (value of threshold) $=0.0,0.2$

- selection method of the comparing company $=\mathbf{a}, \mathbf{b}, \mathbf{c}$

- $\rho=0.01$

In Onozaki-Yanagita model, without the network of consumers, parameter $k$ is the key, which affects the dynamics of market structure. When $k=0.0$, this means that each consumer doesn't behave habitually and change his favorite company rapidly if there is any price difference, shortrun monopolists change immediately (Figure 3). When $k=0.2$, consumer's habitual behavior gets stronger, not only monopoly but oligopoly appears (Figure 4).

However, in extended model, with the network of consumers, appearance is different. The dynamics of the market structure varies due to a selection method of the comparing company, which means how much each consumer can be affected by the information from his acquaintance, not only parameter $k$.

In case of using selection method a or $\mathbf{c}$ as a selection method of the comparing company, the dynamics of market structure looks similar to the 

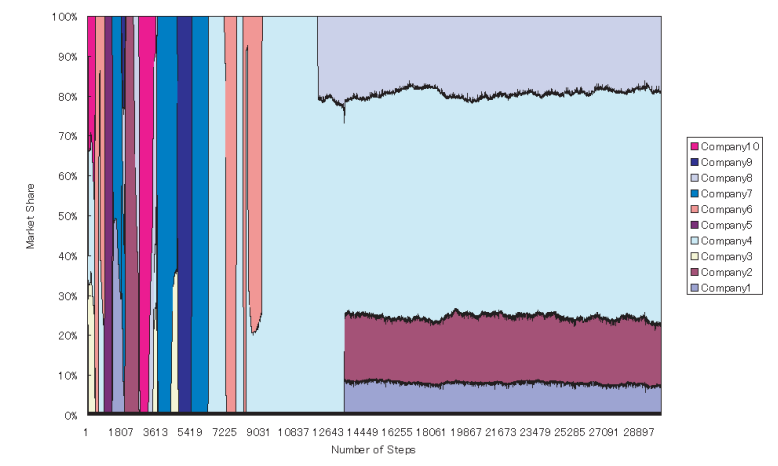

Figure 4: Transition of Each Company's Market Share (Onozaki-Yanagita Model), $k=0.2$
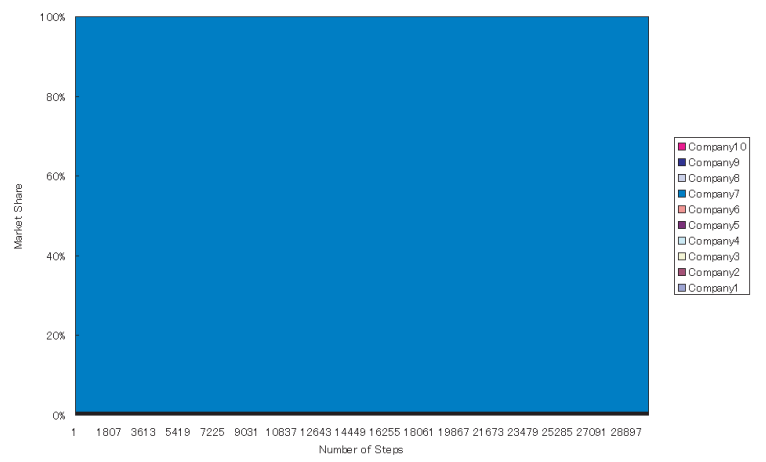

Figure 5: Transition of Each Company's Market Share (Extended Model), $k=0.0$, selection method of the comparing company $=\mathbf{b}$

results of Onozaki-Yanagita model, whether parameter $k=0.0$ or $k=0.2$.

But in case of using selection method $\mathbf{b}$, when $k=0.0$, the market structure will conclude and stay at a monopoly for long time (Figure 5). This is observed with most network structures of consumers. And when $k=0.2$, the market structure will stay at a oligopoly with most network structure of consumers (Figure 6). With "Fully Connected Network", monopoly appears (Figure 7).

\section{Conclusion}

In this paper, we proposed that not only each consumer's own behavior but the interaction between consumers has an impact on shaping and changing a market structure. To realize this idea, we replicated Onozaki-Yanagita model and extended it by adding a network of consumers. Playing the extended model as simulation, we can realize that the network of consumer affects emerging the market structure. We also noticed that the network structures of consumers can influence the market structure.

This model has various possibilities to extend.

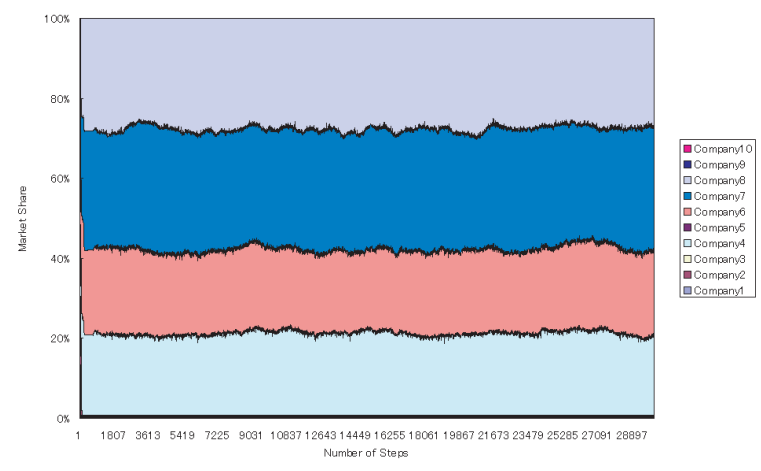

Figure 6: Transition of Each Company's Market Share (Extended Model), $k=0.2$, selection method of the comparing company $=\mathbf{b}$

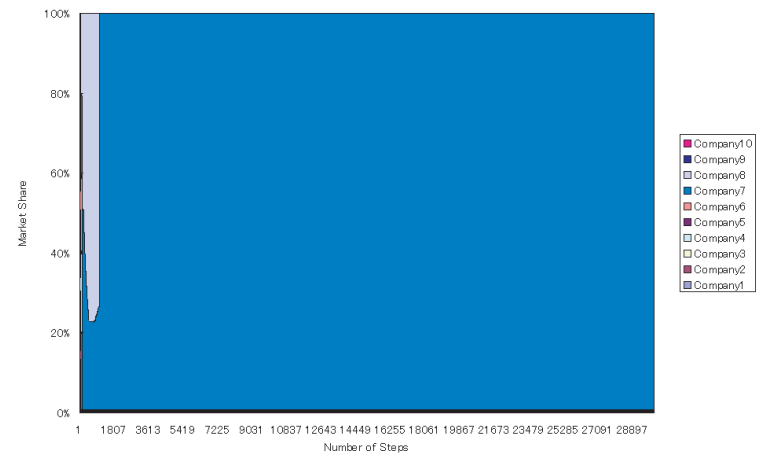

Figure 7: Transition of Each Company's Market Share ( Extended Model), $\mathrm{k}=0.2$, selection method of the comparing company $=\mathbf{b}$

In the future, we would like to try another approach to this model, adding various elements to it. We will also try to increase the number of the Agents and analyze the difference of market structure among various the network of consumers deeper.

\section{References}

[1] Onozaki, T. and Yanagita, T.: "Monopoly, Oligopoly and the Invisible Hand", Discussion Paper Series No.32. The Institute of Economic Research, Chuo University (2002)

[2] Iba, Takashi: "A Framework and Tools for Modeling and Simulating Societies as Evolutionary Complex Systems". 2nd. International Conference of the European Social Simulation Association. (2004)

[3] Iba, Takashi: "Understanding Social Complex Systems with PlatBox Simulator". The 5th International Conference on Computational Intelligence in Economics and Finance. (2006) 